\title{
Kebutuhan Listrik untuk Keadaan Darurat pada Kapal Ferry Ro-Ro KMP. Tuna 600 GRT
}

\author{
Faisal Mahmuddin ${ }^{1 *}$, Musnadi Natsir ${ }^{1}$, Baharuddin $^{1}$ \\ ${ }^{1}$ Departemen Teknik Sistem Perkapalan, Fakultas Teknik, Universitas Hasanuddin \\ Jl. Poros Malino km. 6, Bontomarannu, Kabupaten Gowa, Sulawesi Selatan 92171 \\ *Email: f.mahmuddin@gmail.com
}

DOI: 10.25042/jpe.052019.07

\begin{abstract}
Abstrak
Keselamatan merupakan priorotas utama dalam hukum pelayaran, maka perlu dirancang sedimikian rupa termasuk kebutuhan listrik untuk keadaan darurat/emergency di kapal. Dalam hal kelistrikan, sangat dibutuhkan sistem-sistem yang mendukung pengoprasian menyangkut peralatan apa saja yang harus beroperasi pada kondisi darurat/emergency di kapal. Perencanaan dan pemilihan kapasitas generator harus mampu memenuhi kebutuhan dan harus memperhatikan keefektifan daya generator yang dipilih karena akan berhubungan dengan masalah investasi atau harga yang dikeluarkan. Oleh karena itu, penelitian ini melakukan perhitungan ulang kapasitas generator dan juga melakukan perencanaan/penggambaran ulang diagram kelistrikan (wiring diagram) berdasarkan keadaan di lapangan dan dibandingkan dengan daya output dari generator untuk kondisi darurat/emergency. Dari penelitian ini, dapat dibuktikan secara teoritis bahwa perencanaan sistem kelistrikan di kapal dapat diterapkan secara nyata dan sesuai dengan ketentuan berlaku sehingga pada saat pemasangan instalasi listrik di kapal dan di masa yang akan datang dapat diandalkan demi kepuasan bagi pemilik kapal.
\end{abstract}

\begin{abstract}
Electricity Needs for Emergency Condition on 600 GRT Ro-Ro Ferry of KMP Tuna. Safety is the main priority in shipping law, so it needs to be designed in such a way including electricity needs for emergencies on the ship. In the case of electricity, the electrical systems are needed to support the operation of all equipment which must be operated in an emergency condition on the ship. Planning and selection of generator capacity must be able to meet the needs and must pay attention to the effectiveness of the selected generator power because it will relate to investment matters or the price incurred. Therefore, this research recalculates the capacity of the generator as well as re-plans/redraws the ship electrical (wiring diagram) based on the real situation in the field and compares it with the output power of the generator for emergencies. From this research, it can be proven theoretically that the electrical system planning on the ship can be implemented in a real and in accordance with the applicable provisions so that when installing electrical installations on the ship and in the future can be relied upon for the satisfaction of the ship owner.
\end{abstract}

Kata Kunci: Generator, kapal feri, kondisi darurat, sistem kelistrikan

\section{Pendahuluan}

Kecelakaan dapat terjadi pada kapal baik dalam pelayaran, saat berlabuh ataupun saat sedang melakukan kegiatan bongkar muat di pelabuhan meskipun sudah dilakukan usaha untuk menghindarinya. Manajemen dan pengoperasi kapal harus memperhatikan ketentuan yang diatur untuk melindungi pelaut dan mencegah segala resiko dalam melakukan aktifitas diatas kapal terutama yang menyangkut keselamatan kerja, baik dalam keadaan normal maupun darurat.

Kondisi normal pelayaran adalah suatu kondisi dimana sistem pada kapal seperti permesinan, layanan kelistrikan, usaha maupun sistem propulsi mampu mengendalikan pelayaran dengan aman. Aman yang dimaksudkan adalah aman dari kebocoran dan kebakaran. Selain itu, komunikasi internal dan eksternal, jalan penyelamatan darurat dan winch sekoci telah sesuai dengan rancangan berada dalam kondisi memuaskan dan bekerja dengan baik dan berfungsi normal [1].

Sedangkan kondisi darurat adalah suatu kondisi dimana kebutuhan pelayaran untuk beroperasi normal tidak bekerja dengan baik akibat kegagalan pasokan dari sumber listrik 
utama. Pada kondisi darurat ini, satu atau lebih generator digunakan untuk memenuhi kebutuhan listrik untuk menjamin jalannya sistem keselamatan kemaritiman di kapal. Terutama pada alat-alat keselamatan yang membutuhkan supply listrik, sehingga alat keselamatan berfungsi sebagaimana fungsinya masing-masing [2].

Untuk menjamin berlangsungnya supply listrik secara baik pada kondisi darurat ini maka sebuah kapal feri Ro-Ro yang beroperasi pada rute Bajoe-Kolaka yang diberi nama KMP Tuna melakukan penambahan sebuah generator darurat. Hanya saja, karena generator darurat ini merupakan peralatan tambahan maka peralatan ini belum diupdate kedalam sistem kelistrikan (wiring diagram) dari kapal yang dimaksud. Untuk itu perlu sebuah usaha untuk merencanakan ulang atau menggambar ulang wiring diagram dari KMP. Tuna sehingga sistem kelistrikan kapal dapat bekerja dengan aman dan handal.

\section{Generator}

Generator adalah mesin listrik yang merubah energi mekanik menjadi energi listrik dengan menggunakan prinsip induksi magnet. Sedangkan yang dimaksud dengan prinsip induksi magnet adalah saat sebuah konduktor digerakkan pada medan magnet sehingga gerakan konduktor memotong flux magnetik. Pada kapal biasanya digunakan generator $\mathrm{AC}$ atau lebih dikenal dengan istilah alternator.

Baik pada generator DC maupun AC, konstruksi dasarnya berupa konduktor sebagai penghasil tegangan dan sebuah bagian yang menghasilkan medan magnet. Sebagai representasi dari kedua bagian tersebut, setiap generator pasti memiliki rotor dan stator. Rotor merupakan bagian yang berputar dan stator merupakan bagian yang diam. Pada generator DC, penghasil tegangan adalah rotor sedangkan pada generator $\mathrm{AC}$, baik rotor maupun stator dapat menghasilkan tegangan.

Untuk generator AC dengan rotor sebagai penghasil tegangan, konstruksi hampir sama DC dengan generator, hanya saja tegangan yang dihasilkan tidak diserahkan dengan komutator, melainkan langsung dialirkan melalui slipring dan arus penguat dialirkan menuju bagian stator.
Generator dengan tipe seperti ini biasanya digunakan untuk memasok kebutuhan listrik yang tidak besar. Sedangkan untuk generator AC dengan stator sebagai penghasil tegangan, arus penguat dialirkan menuju rotor sehingga saat rotor berputar, terjadi medan putar. Keuntungan sistem ini adalah tegangan yang dihasilkan dapat langsung dihubungkan dengan beban listrik dan dapat mengurangi resiko short circuit karena tidak menggunakan slip ring ataupun sikat arang sebagai pengalir tegangan yang dihasilkan, karena slip ring dan sikat arang merupakan komponen yang sulit untuk diisolasi [3].

Pada kapal KMP. Tuna sumber listrik generator set daya output berupa arus AC dan batterai daya output berupa arus DC. Sumber listrik batterai digunakan hanya untuk peralatan yang membutuhkan sistem pengaktifan dari arus DC dan dalam keadaan darurat seperti pada alat navigasi, alat komunikasi dan peralatan lainnya. Dan untuk sumber listrik generator (AC) di kapal, tapi tidak semua peralatan di kapal memerlukan arus AC untuk system pengaktifannya. Maka perlu di rancang sedimikian rupa agar sumber arus listrik AC yang masuk diubah menjadi arus DC agar peralatan yang memerlukan system pengaktifannya bisa digunakan sebagaimana mestinya.

\section{Metode Penelitian}

\subsection{Lokasi dan Waktu Penelitian}

Penelitian ini dilakukan di Pelabuhan Ferry Bajoe-Kolaka dan waktu pengambilan data yaitu pada bulan Maret 2013.

\subsection{Metode Pengambilan Data}

Penelitian dilakukan langsung di lapangan atau lokasi penelitian dengan melakukan pengamatan langsung terhadap objek yang akan diteliti untuk mendapatkan data utama maupun data pendukung yang dibutuhkan.

\subsection{Data Kapal}

- Data Umum

- Nama Kapal: KMP.Tuna

- Jenis Kapal: Ferry Ro-Ro

- Kebangsaan: Indonesia 
- Tahun Pembuatan: 1992

- Tempat Pembuatan: Surabaya

- Trayek: Bajoe-Kolaka

- Ukuran Utama

- LOA: $45.30 \mathrm{~m}$

- Lbp: $38.50 \mathrm{~m}$

- B: $14 \mathrm{~m}$

- $\mathrm{H}: 3.50 \mathrm{~m}$

- $\quad \mathrm{T}: 2.10 \mathrm{~m}$

- V: 11.5 Knot

- Data Mesin dan Generator

- Main Engine: NIGATA 6NSC-M, 900 HP x 1000 RPM, 2 buah

- Generator Utama: PERKINS TG.3544 100 HP, 1500 RPM, 2 buah, Capacity : 80 KVA / 64 kW, Faktor daya $(\operatorname{Cos} \varnothing)$ : 0.8

- Generator emergency: PERKINS MODEL YEARA 2008, Capacity 31 kW, Faktor daya $(\operatorname{Cos} \varnothing)$ : 0.8

- Data Peralatan dan Penerangan

Tabel 1. Peralatan pada kamar mesin

\begin{tabular}{|c|c|c|c|}
\hline No & Nama Peralatan & Unit & $\begin{array}{c}\text { Daya } \\
(\mathbf{k W}) / \\
\text { Unit }\end{array}$ \\
\hline 1 & Bilge / Ballast Pump & 2 & 3.7 \\
\hline 2 & Sea Water Hydrophore Pump & 1 & 0.375 \\
\hline 3 & $\begin{array}{l}\text { Fresh Water Hydrophore } \\
\text { Pump }\end{array}$ & 1 & 0.375 \\
\hline 4 & Fuel Oil Transfer Pump & 1 & 1.1 \\
\hline 5 & Sewage Pump & 1 & 3.7 \\
\hline 6 & Oil Bilge Pump & 1 & 1.5 \\
\hline 7 & Oil Water Separator & 1 & 0.4 \\
\hline 8 & Air Compressor & 1 & 3 \\
\hline 9 & $\begin{array}{l}\text { Stand-by L.O Pump for Main } \\
\text { Engine }\end{array}$ & 1 & 2.2 \\
\hline 10 & $\begin{array}{l}\text { Stand-by Lubrication Oil } \\
\text { Pump for Gear Box }\end{array}$ & 1 & 2.2 \\
\hline 11 & $\begin{array}{l}\text { Pompa Hidrophore Mesin } \\
\text { Jangkar/Pintu pendarat depan }\end{array}$ & 1 & 18.5 \\
\hline 12 & $\begin{array}{l}\text { Pompa Hidrophore Pintu } \\
\text { pendarat belakang }\end{array}$ & 1 & 15 \\
\hline 13 & $\begin{array}{l}\text { Pompa Hidropohore Mesin } \\
\text { Kemudi }\end{array}$ & 1 & 5 \\
\hline 14 & $\begin{array}{l}\text { Peralatan Radio, Telephone, } \\
\text { SSB, Radar, dan lain-lain. }\end{array}$ & 1 & 1 \\
\hline 15 & $\begin{array}{l}\text { Fan Kamar ABK, Mes, dan } \\
\text { lain-lain. }\end{array}$ & 1 & 0.75 \\
\hline
\end{tabular}

\begin{tabular}{clcc}
\hline No & Nama Peralatan & Unit & $\begin{array}{c}\text { Daya } \\
(\mathbf{k W}) / \\
\text { Unit }\end{array}$ \\
\hline 16 & Exhaust/Fan Dapur, WC & 1 & 0.6 \\
17 & Fan Ruang Penumpang & 2 & 2.2 \\
18 & Ventilasi Kamar Mesin & 2 & 2.2 \\
\hline
\end{tabular}

Tabel 2. Peralatan penerangan

\begin{tabular}{|c|c|c|c|}
\hline No & Nama Peralatan & Unit & $\begin{array}{c}\text { Daya }(\mathbf{W}) / \\
\text { Unit }\end{array}$ \\
\hline 1 & Musthead Light & 2 & 40 \\
\hline 2 & Side Light & 2 & 40 \\
\hline 3 & Stern Light & 1 & 40 \\
\hline 4 & Anchor Light & 1 & 40 \\
\hline 5 & Morse Signal Light & 1 & 40 \\
\hline 6 & Search Light & 1 & 500 \\
\hline 7 & Chart Table Light & 1 & 15 \\
\hline 8 & $\begin{array}{l}\text { Double Fluorescent } \\
\text { Light }\end{array}$ & 48 & $20 \times 2$ \\
\hline 9 & $\begin{array}{l}\text { Single Fluorescent } \\
\text { Light }\end{array}$ & 8 & 20 \\
\hline 10 & $\begin{array}{l}\text { Ceiling Light (Non } \\
\text { Water Tight) }\end{array}$ & 10 & 20 \\
\hline 11 & $\begin{array}{l}\text { Desk Light (Non Water } \\
\text { Tigth) }\end{array}$ & 10 & 10 \\
\hline 12 & $\begin{array}{l}\text { Berth Light (Non Water } \\
\text { Tight) }\end{array}$ & 17 & 10 \\
\hline 13 & Exhaust Fan & 13 & 75 \\
\hline 14 & Supply Fan & 15 & 75 \\
\hline 15 & Projector Light & 4 & 200 \\
\hline 16 & White Light & 3 & 5 \\
\hline 17 & Red Light & 4 & 5 \\
\hline 18 & Green Light & 3 & 5 \\
\hline 19 & $\begin{array}{l}\text { Incandescent lamp, } \\
\text { Non Watertight untuk } \\
\text { penerangan tangga. }\end{array}$ & 6 & 40 \\
\hline
\end{tabular}

\section{Hasil dan Pembahasan}

\subsection{Penentuan kebutuhan generator darurat}

Dalam penentuan kapasitas generator yang akan digunakan untuk melayani kebutuhan listrik diatas kapal, baik itu kapal beroperasi dalam kondisi normal ataupun dalam kondisi emergency, maka analisa beban dibuat untuk menentukan jumlah daya yang dibutuhkan. Dalam hal ini dimaksudkan untuk mengetahui daya maksimum yang dibutuhkan untuk setiap kondisi. 


\subsubsection{Daya untuk keadaan normal (DN)}

Adapun peralatan-peralatan pada kapal ferry Ro-Ro KMP. Tuna yang membutuhkan listrik sebagai tenaga penggeraknya terbagi atas alat permesinan dan alat penerangan yang dapat dilihat pada Tabel 3 dan Tabel 4 berikut :

Tabel 3. Alat permesinan untuk daya normal

\begin{tabular}{|c|c|c|c|c|}
\hline No & Nama Peralatan & Unit & $\begin{array}{c}\text { Daya } \\
(\mathbf{k W}) / \\
\text { Unit }\end{array}$ & $\begin{array}{l}\text { Total } \\
\text { Daya } \\
(\mathrm{kW})\end{array}$ \\
\hline 1 & Bilge/Ballast Pump & 2 & 3.7 & 7.4 \\
\hline 2 & $\begin{array}{l}\text { Sea Water } \\
\text { Hydrophore Pump }\end{array}$ & 1 & 0.375 & 0.375 \\
\hline 3 & $\begin{array}{l}\text { Fresh Water } \\
\text { Hydrophore Pump }\end{array}$ & 1 & 0.375 & 0.375 \\
\hline 4 & $\begin{array}{l}\text { Fuel Oil Transfer } \\
\text { Pump }\end{array}$ & 1 & 1.1 & 1.1 \\
\hline 5 & G.S. Fire Pump & 1 & 5.5 & 5.5 \\
\hline 6 & Sewage Pump & 1 & 3.7 & 3.7 \\
\hline 7 & Oil Bilge Pump & 1 & 1.5 & 1.5 \\
\hline 8 & Oil-Water Separator & 1 & 0.4 & 0.4 \\
\hline 9 & Air Compressor & 1 & 3 & 3 \\
\hline 10 & $\begin{array}{l}\text { Stand-by L.O. Pump } \\
\text { for Main Engine }\end{array}$ & 1 & 2.2 & 2.2 \\
\hline 11 & $\begin{array}{l}\text { Stand-by L.O. Pump } \\
\text { for Gear Box } \\
\text { Pompa Hidrophore }\end{array}$ & 1 & 2.2 & 2.2 \\
\hline 12 & $\begin{array}{l}\text { Mesin Jangkar/ Pintu } \\
\text { pendarat depan } \\
\text { Pompa Hidrophore }\end{array}$ & 1 & 18.5 & 18.5 \\
\hline 13 & $\begin{array}{l}\text { Pintu pendarat } \\
\text { belakang }\end{array}$ & 1 & 15 & 15 \\
\hline 14 & $\begin{array}{l}\text { Pompa Hidropohore } \\
\text { Mesin Kemudi }\end{array}$ & 1 & 5 & 5 \\
\hline 15 & $\begin{array}{l}\text { Peralatan } \\
\text { Radio,Telephone, } \\
\text { SSB, Radar, dll. }\end{array}$ & 1 & 1 & 1 \\
\hline 16 & $\begin{array}{l}\text { Fan Kamar ABK, } \\
\text { Mess, dll. }\end{array}$ & 1 & 0.75 & 0.75 \\
\hline 17 & $\begin{array}{l}\text { Exhaust Fan Dapur, } \\
\text { KM / WC }\end{array}$ & 1 & 0.6 & 0.6 \\
\hline 18 & $\begin{array}{l}\text { Fan Ruang } \\
\text { Penumpang }\end{array}$ & 2 & 2.2 & 4.4 \\
\hline 19 & $\begin{array}{l}\text { Ventilasi Fan Kamar } \\
\text { Mesin }\end{array}$ & 2 & 2.2 & 4.4 \\
\hline \multicolumn{4}{|c|}{ Total } & 26.8 \\
\hline
\end{tabular}

Tabel 4. Alat penerangan pada kapal

\begin{tabular}{|c|c|c|c|c|}
\hline No & Nama Peralatan & Unit & $\begin{array}{l}\text { Daya } \\
\text { (W)/ } \\
\text { Unit }\end{array}$ & $\begin{array}{l}\text { Total } \\
\text { Daya } \\
\text { (W) }\end{array}$ \\
\hline 1. & Musthead Light & 2 & 40 & 80 \\
\hline 2. & Side Light & 2 & 40 & 80 \\
\hline 3. & Stern Light & 1 & 40 & 40 \\
\hline 4. & Anchor Light & 1 & 40 & 40 \\
\hline 5. & Morse Signal Light & 1 & 40 & 40 \\
\hline 6. & Search Light & 1 & 500 & 500 \\
\hline 7. & Chart Table Light & 1 & 15 & 15 \\
\hline 8. & $\begin{array}{l}\text { Double Fluorescent } \\
\text { Light }\end{array}$ & 48 & $20 \times 2$ & 1920 \\
\hline 9. & Single Fluorescent Light & 8 & 20 & 160 \\
\hline 10. & $\begin{array}{l}\text { Ceiling Light (Non } \\
\text { Water Tight) }\end{array}$ & 10 & 20 & 200 \\
\hline 11. & $\begin{array}{l}\text { Desk Light (Non Water } \\
\text { Tigth) }\end{array}$ & 10 & 10 & 100 \\
\hline 12. & $\begin{array}{l}\text { Berth Light (Non Water } \\
\text { Tight) }\end{array}$ & 17 & 10 & 170 \\
\hline 13. & Exhaust Fan & 13 & 75 & 975 \\
\hline 14. & Supply Fan & 15 & 75 & 1125 \\
\hline 15. & Lampu Projector & 4 & 200 & 800 \\
\hline 16. & $\begin{array}{l}\text { White Light (Pada } \\
\text { MCB) }\end{array}$ & 3 & 5 & 15 \\
\hline 17. & Red Light (Pada MCB) & 4 & 5 & 20 \\
\hline 18. & $\begin{array}{l}\text { Green Light (Pada } \\
\text { MCB) } \\
\text { Incandescent lamp, Non }\end{array}$ & 3 & 5 & 15 \\
\hline 19. & $\begin{array}{l}\text { Water Tight untuk } \\
\text { penerangan tangga. }\end{array}$ & 6 & 40 & 240 \\
\hline
\end{tabular}

Jadi total penggunaan listrik untuk kondisi normal (DN) adalah

$\mathrm{DN}=$ daya alat pemesinan + daya alat penerangan $=26.8+6.575=33.375 \mathrm{~kW}$

\subsubsection{Daya untuk kondisi emergency}

Sesuai dengan peraturan BKI (BKI Volume 1V, Rules for Electrical Installation Section 2, "Instalation of electrical Equipment") [4], menjelaskan tentang alat-alat apa saja yang harus beroperasi pada saat kondisi darurat/emergency menjadi patokan dalam perhitungan beban listrik dan bisa menjadi acuan dalam pemilihan generator yang bisa dipertimbangkan dari segi ekonomisnya. 
Adapun data penelitian diperoleh berdasarkan hasil studi lapangan dan studi literatur, selanjutnya dilakukan pengolahan data berupa perhitungan kebutuhan daya listrik di kapal, baik itu dalam kondisi normal maupun dalam kondisi darurat. Untuk kondisi darurat, sebelumnya sudah dijelaskan bahwa penyebab kegagalan sistem listrik utama hanya diasumsikan dan tidak dibahas lebih lanjut sedangkan kondisi emergency yang dimaksud pada saat generator utama dalam kondisi blackout. Adapun letak generator emergency tersebut terletak pada kamar yang ada pada deck kendaraan.

Kondisi emergency kapal harus mempertimbangkan beban apa saja yang harus disuplai listrik dalam waktu yang singkat. Daya terbesar yang terjadi pada kondisi darurat adalah pada saat starting. Adapun peralatan permesinan dan alat penerangan yang harus disupply berdasarkan referensi yang ada dapat dilihat pada Tabel 5 berikut.

Tabel 5. Peralatan dan penerangan untuk kondisi emergency (DE)

\begin{tabular}{|c|c|c|c|c|}
\hline No & Nama Peralatan & Unit & $\begin{array}{c}\text { Daya } \\
\text { (kW)/ } \\
\text { Unit }\end{array}$ & $\begin{array}{l}\text { Total } \\
\text { Daya } \\
(\mathbf{k W})\end{array}$ \\
\hline 1 & Bilge/Ballast Pump & 2 & 3.7 & 7.4 \\
\hline 2 & $\begin{array}{l}\text { Pompa Dinas } \\
\text { Umum/Kebakaran }\end{array}$ & 1 & 3.3 & 3.3 \\
\hline 3 & $\begin{array}{l}\text { General Service/Fire } \\
\text { Pump } \\
\text { Pendant Light (Water }\end{array}$ & 1 & 5.5 & 5.5 \\
\hline 4 & $\begin{array}{l}\text { Tight), Emergency } \\
\text { Lamp } \\
\text { Pendant Light (Non }\end{array}$ & 23 & 0.010 & 0.23 \\
\hline 5 & $\begin{array}{l}\text { Water Tight), } \\
\text { Emergency Lamp }\end{array}$ & 21 & 0.010 & 0.21 \\
\hline 6 & Musthead Light & 2 & 0.040 & 0.08 \\
\hline 7 & Side Light & 2 & 0.040 & 0.08 \\
\hline 8 & Stern Light & 1 & 0.040 & 0.04 \\
\hline 9 & Anchor Light & 1 & 0.040 & 0.04 \\
\hline 10 & Morse Signal Light & 1 & 0.040 & 0.04 \\
\hline 11 & $\begin{array}{l}\text { Search Light } \\
\text { Peralatan Radio, }\end{array}$ & 1 & 0.5 & 0.5 \\
\hline 12 & $\begin{array}{l}\text { Telephone, SSB, } \\
\text { Radar, dan lain-lain. } \\
\text { Incandescent Lamp, } \\
\text { (Non Water Tight), } \\
\text { Lampu Penerangan } \\
\text { Tangga }\end{array}$ & 1 & 0.04 & 0.24 \\
\hline \multicolumn{4}{|c|}{ Total } & 18.58 \\
\hline
\end{tabular}

Jadi total daya untuk keadaan emergensi (DE) adalah $18.58 \mathrm{~kW}$.

\subsection{Presentase Pemakaian Generator}

Perhitungan presentase pemakaian generator untuk peralatan permesinan dan penerangan dapat diketahui dengan menggunakan persamaan atau dapat dirumuskan sebagai berikut [5]:

$$
\eta=\frac{P o}{P i} \times 100 \%
$$

dimana:

$$
\begin{aligned}
\eta= & \text { Presentase pemakaian } \\
P o= & \text { Daya peralatan yang dibutuhkan } \\
P i= & \text { Daya generator generator yang } \\
& \text { tersedia }
\end{aligned}
$$

Untuk presentase pemakaian generator utama didapatkan nilai efesiensi sebagai berikut:

$$
\begin{aligned}
\eta & =\frac{33.375 \mathrm{~kW}}{64 \mathrm{~kW}} \times 100 \% \\
& =52.15 \%
\end{aligned}
$$

Sedangkan presentase pemakaian generator emergency adalah sebagai berikut:

$$
\begin{aligned}
\eta & =\frac{18.58}{31.3} \times 100 \% \\
& =59.36 \%
\end{aligned}
$$

Dilihat dari presentase daya kebutuhan listrik untuk kondisi darurat / emergency efesiensi yang di dapat sebesar $59.36 \%$. Dari nilai presentase ini, terlihat bahwa banyak daya yang terbuang (tidak difungsikan), sehingga dapat dianggap tidak efesien dari segi ekonomisnya.

Untuk memenuhi daya listrik untuk kebutuhan darurat/emergency dari perhitungan daya sebesar $18.58 \mathrm{~kW}$, dapat direkomendasikan generator yang efektif untuk KMP. Tuna dari segi ekonomis yang ada di pasar yaitu PERKINS 404D-22G dengan kapasitas daya sebesar $20.3 \mathrm{~kW}$ agar daya generator tidak banyak yang terbuang sehingga pemakaian generator lebih efektif dan efesien. 


\subsection{Update Wiring Diagram}

Akibat penambahan generator, maka diagram kelistrikan (wiring diagram) dari kapal KMP. Tuna juga harus dirubah atau digambar ulang. Adapun wiring diagram yang dan yang baru dapat dilihat pada Gambar 1 dan 2, masing-masing.

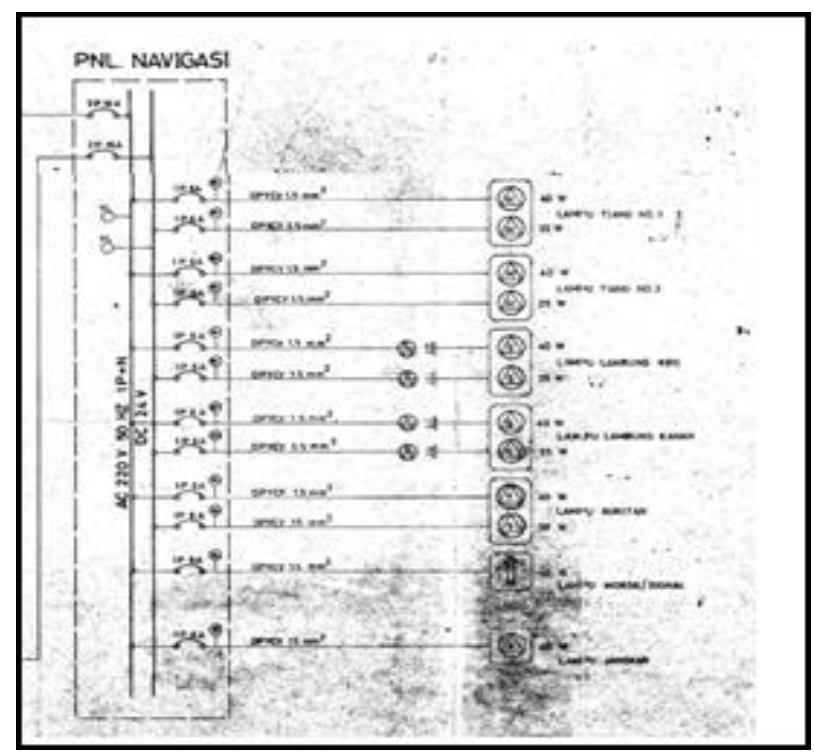

Gambar 1. Wiring diagram sebelum pemasangan generator emergency

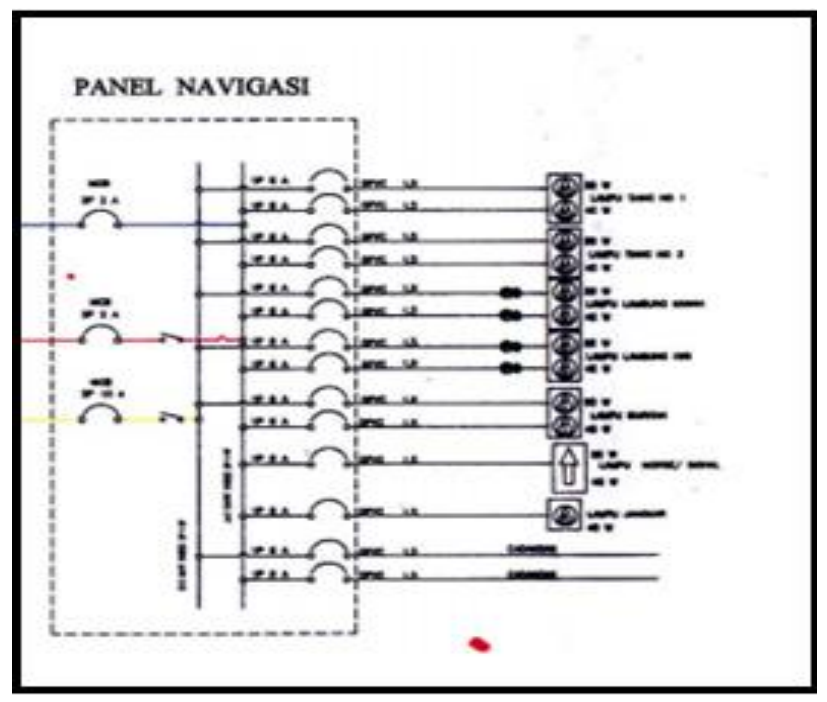

Gambar 2. Wiring diagram setelah pemasangan generator emergency

Dari Gambar 1 dapat dilihat bahwa KMP. Tuna sebelumnya hanya memiliki 4 sumber listrik. Dimana generator dipakai untuk sumber listrik dalam keadaan normal sedangkan battery digunakan untuk kondisi emergency. Adapun gambar wiring diagram listrik tersebut setelah adanya penambahan dapat dilihat pada Gambar 2 .

Untuk sistem emergency di kapal, BKI Rules Volume 4 Rules for Electrical Installation, Section 2 "Instalation of Electrical Equipment" menyatakan dibutuhkan generator emergency untuk menopang kinerja seluruh peralatan yang diperlukan pada saat kondisi emergency. Sebelumnya sudah dijelaskan peralatan apa saja yang harus diaktifkan pada kondisi emergency. Dan dilihat pada gambar wiring diagram terdapat warna yang dapat mempermudah pembaca. Dimana diantaranya sebagai berikut :

- Biru adalah sumber listrik dari generator utama

- Merah adalah sumber listrik dari generator emergency

- Kuning adalah sumber listrik dari battery

Dari Gambar 2 dapat dilihat bahwa generator darurat yang ditambahkan di wiring diagram dapat mendukung layanan kelistrikan saat kondisi darurat tanpa mengganggu sistem kelistrikan pada kondisi normal.

\section{Kesimpulan}

Dari hasil perhitungan dan penganalisaan pada dan dengan memperhatikan tiap kondisi kapal, maka ditarik beberapa kesimpulan

- Dari hasil perhitungan kebutuhan daya operasional tiap kondisi, dinyatakan masih cukup untuk memenuhi kebutuhan listrik pada kapal. Adapun nilai-nilai yang dimaksud adalah sebagai berikut :

- Kondisi Normal : $: 33.375 \mathrm{~kW}$

- Kondisi Emergensi : $18.58 \mathrm{~kW}$

- Nilai presentase pemakaian generator tiap kondisi adalah sebagai berikut :

- Kondisi Normal : $52.15 \%$

- Kondisi Emergensi : $59.36 \%$

Sehingga diketahui bahwa daya generator yang tersedia memenuhi baik pada kondisi normal maupun kondisi darurat/emergency.

\section{Referensi}

[1] International of Maritime Organization (IMO), SOLAS (Safety of Life at Sea) Chapter 2, 2004. 
[2] Harrington, Roy, "Marine Engineering", SNAME, [4] BKI (Biro Klasifikasi Indonesia), Volume IV Rules for 1992, New York. Electrical Instalation", Section 2, BKI, Jakarta.

[3] Watson, George Opli Phant, "Marine Electrical Practice" Butterworth \& Co, 1983, London.

[5] Watkins A.J, "Perhitungan Instalasi Listrik", diterjemahkan oleh Ir. Zulkifli Harahap, 2004. 